\title{
Avaliação do ganho compensatório em novilhos mestiços Holandês-Gir: consumo e desempenho
}

\section{Carlos Augusto de Alencar Fontes ${ }^{1}$, Rodrigo Furtado Machado Guimarães ${ }^{2}$, Maria Izabel Vieira de Almeida ${ }^{3}$, Oriel Fajardo de Campos ${ }^{4}$, Fernando Queiroz de Almeida ${ }^{5}$, Nivaldo de Faria Sant'Ana ${ }^{6}$}

\author{
${ }^{1}$ LZNA/UENF. Bolsista do CNPq. \\ 2 Zootecnista, M.Sc., Autônomo. \\ 3 UFES. \\ ${ }^{4}$ Embrapa Gado de Leite. Bolsista do CNPq. \\ ${ }^{5}$ UFRRJ. Bolsista do CNPq \\ ${ }^{6}$ Doutorando em Produção Animal, M.Sc., LZNA/UENF. Bolsista da FAPERJ.
}

RESUMO - Avaliou-se a influência da restrição alimentar durante um período de pastejo de 104 dias (fase 1) sobre o consumo e a conversão alimentar, o conteúdo de digesta no trato gastrintestinal e os ganhos de peso corporal, da carcaça e dos constituintes não-carcaça em bovinos durante o período de realimentação em confinamento (fase 2). Foram utilizados 39 novilhos mestiços Holandês-Gir, com idade inicial de 19,3 $\pm 5,1$ meses e 202,0 $\pm 49,1 \mathrm{~kg}$ de PV, distribuídos em três grupos segundo o regime alimentar proposto: controle - pastejo ad libitum na fase 1 e ração ad libitum na fase 2 (nove animais); ganho compensatório - pastejo restrito na fase 1 e ração ad libitum na fase 2 (15 animais); mantença - pastejo restrito na fase 1 e níveis de proteína e energia 15\% acima da mantença na fase 2 (15 animais). Nos dias 1, 28, 56, 84 e 112 de confinamento, foram abatidos três animais do regime ganho compensatório e três do regime de mantença. Nos dias 1 , 28 e 112 , foram igualmente abatidos três animais do grupo controle. Em comparação aos animais do grupo controle, os novilhos do ganho compensatório ganharam mais peso corporal durante os primeiros 28 dias de confinamento (ganharam mais peso dos constituintes não-carcaça), porém, não diferiram quanto ao ganho de peso da carcaça. Após o início do confinamento, com a ingestão de alimentos concentrados, verificou-se redução contínua do conteúdo de digesta (em \% PV) nos animais dos três regimes de alimentação, mas não foi observada diferença entre os regimes de alimentação. Nos grupos controle e ganho compensatório, os 28 dias iniciais de confinamento constituíram o período de melhor conversão alimentar, pois coincidiram com o período de maior consumo por unidade de tamanho metabólico e em porcentagem do peso vivo.

Palavras-chave: carcaça, conversão alimentar, digesta, ganho de peso

\section{Evaluation of compensatory growth in crossbred Holstein-Gyr steers: intake and performance}

\begin{abstract}
The objective of this trial was to evaluate the effect of feed restriction during a grazing period of 104 days (phase I) on intake, feed conversion, and digesta load as well as body weight (BW) change and weights of carcass and non-carcass components during a feedlot period (phase II) in crossbred steers. Thirty nine crossbred Holstein-Gyr steers averaging $19.3 \pm 5.1$ months of age and $202.0 \pm 49.1 \mathrm{~kg}$ of BW at the beginning of the study were used. Animals were assigned to one of the following three treatments: 1 - control - ad libitum grazing in phase I and ad libitum concentrate in phase II (nine animals); 2 - compensatory growth - restricted grazing in phase I and ad libitum concentrate in phase II (15 animals); or 3 - maintenance - restricted grazing in phase I and protein and energy supplementation 15\% above maintenance in phase II (15 animals). At 1, 28, and 112 days of feedlot, three animals from treatments 1,2 and 3 were slaughtered. In addition, three animals from treatments 2 and 3 were also slaughtered at 56 and 84 days of feedlot. Animals from the compensatory growth treatment gained more BW than those from the control during the first 28 days of feedlot because of the greater weight gain of non-carcass components. However, carcass weight gain did not differ between both treatments. Gut fill as percentage of BW decreased in all three treatments when animals were fed concentrate in phase 2 but no significant differences were observed across treatments. Animals on control and compensatory growth treatments had improved feed conversion during the first 28 days of feedlot, which was associated to greater intake either expressed per unit of metabolic size or as percentage of $\mathrm{BW}$.
\end{abstract}

Key Words: carcass, digesta, feed conversion, weight gain 


\section{Introdução}

No Brasil, a contribuição do macho de origem leiteira na produção de carne está muito aquém de seu potencial. Os bezerros originários de criatórios da raça holandesa normalmente são abatidos logo após o nascimento ou criados em condições precárias (Lucci, 1989; Campos et al., 1996), o que compromete seu potencial produtivo.

O desenvolvimento de sistemas racionais de produção que permitam o aproveitamento desses animais requer maior conhecimento do fenômeno do ganho compensatório. Ryan (1990) definiu ganho compensatório como a taxa de crescimento acima do normal, algumas vezes observadas após um período de restrição nutricional, que tenha resultado em ligeiro aumento, em manutenção ou redução do peso vivo do animal e cuja duração tenha sido suficiente para permitir sua adaptação ao estado nutricional mais baixo. $\mathrm{O}$ crescimento compensatório e severidade e duração do período da restrição, podendo ocorrer completa ou parcial recuperação do ganho de peso, dependendo da persistência da taxa de ganho adicional, ou mesmo não ocorrer qualquer compensação (Ryan, 1990; Hogg, 1991; Nicol \& Kitessa, 1995; Sainz, 1998).

Segundo Ryan (1990), um dos mecanismos que causam crescimento compensatório é o aumento no consumo de energia. O consumo durante o período de realimentação não é constante, podendo ocorrer um período de adaptação de 3 a 4 semanas antes de os animais em ganho compensatório atingirem níveis de consumo semelhantes aos daqueles sem restrição nutricional (controle). Após esse período, podem apresentar consumo alimentar mais elevado que o daqueles do grupo controle. Entretanto, isso normalmente ocorre apenas quando as dietas são ricas em energia e a limitação do consumo não se dá por mecanismo de distensão. Com o aumento do consumo, pode ocorrer aumento do conteúdo da digesta no trato digestivo.

De acordo com alguns pesquisadores (Ryan, 1990; Hogg, 1991; Sainz, 1998), durante o período de restrição alimentar, ocorrem mudanças no perfil hormonal dos animais e redução do tamanho dos órgãos metabolicamente ativos, ligados à função digestiva. A extensão em que ocorre a redução do tamanho desses órgãos, segundo esses autores, influencia a resposta compensatória, em decorrência da relação direta entre o tamanho dos órgãos e as exigências de energia de mantença do animal. Nesse sentido, Sainz (1998) verificou que bovinos submetidos à restrição alimentar recebendo forragem de baixo valor nutritivo à vontade tiveram ao final do período de restrição peso dos quatro compartimentos do estômago $28 \%$ maior que o daqueles alimentados ad libitum com dieta rica em concentrado. Por outro lado, houve redução dos compartimentos estomacais nos animais submetidos à restrição e limitados à ingestão da dieta rica em concentrado. No início do período de realimentação, os animais alimentados com forragem à vontade tiveram exigência de energia de mantença $21 \%$ superior à daqueles do grupo controle, enquanto a exigência dos alimentados ad libitum com dieta rica em concentrado foi $17 \%$ inferior.

Herson et al. (2004) também concluíram que novilhos previamente submetidos à restrição alimentar pastejando no inverno forrageiras nativas dormentes tiveram maior exigência de energia de mantença na fase de terminação em confinamento.

Este trabalho foi conduzido com o objetivo de avaliar a influência do ganho compensatório sobre o consumo, os ganhos de peso vivo, de carcaça e dos componentes nãocarcaça e a conversão alimentar de novilhos mestiços Holandês-Gir.

\section{Material e Métodos}

O experimento foi realizado no Campo Experimental Fazenda Santa Mônica, da Embrapa Gado de Leite, sendo constituído de duas fases: na primeira, com início no fim da estação seca (começo de outubro) e duração de 104 dias, os animais foram mantidos em pastejo; e, na segunda, com duração de 112 dias, os animais foram mantidos em confinamento. Foram utilizados 39 novilhos mestiços Holandês-Gir, castrados, no mínimo 7/8 Holandês, com peso vivo inicial de 202,1 $\pm 49,1 \mathrm{~kg}$ e 19,3 $\pm 5,1$ meses de idade, medidos no término da época seca (inicio da fase 1), distribuídos em três blocos, de acordo com o peso vivo inicial.

$\mathrm{Na}$ fase 1 (período de pastejo), nove animais escolhidos ao acaso, três de cada bloco, foram mantidos em pastagens de capim-braquiária (Brachiaria decumbens), de acordo com o manejo usual da fazenda, procurando-se não impor restrição ao consumo de forragem (grupo controle). Os trinta animais restantes, dez de cada bloco, foram mantidos em pastagem semelhante, elevando-se a taxa de lotação de forma a reduzir a seletividade de pastejo e obter ganhos de peso próximos a $100 \mathrm{~g} / \mathrm{dia}$ (grupo de pastejo restrito). No final da fase 1, antes de serem confinados, os animais foram tratados contra endo e ectoparasitos e receberam 1.500.000 UI de vitamina A injetável.

Na fase 2 (período de confinamento), os animais foram distribuídos em três grupos, segundo o regime alimentar a que foram submetidos na fase 1 (período de pastejo): controle - pastejo ad libitum na fase 1 e ração ad libitum 
na fase 2 (nove animais, três de cada bloco); ganho compensatório - pastejo restrito na fase 1 e ração ad libitum na fase 2 (15 animais, cinco de cada bloco, escolhidos ao acaso); mantença - pastejo restrito na fase 1 e ração em quantidade limitada na fase 2 , para suprir níveis de proteína e energia $15 \%$ acima das exigências de mantença (15 animais, cinco de cada bloco, escolhidos ao acaso). A análise dos dados foi feita utilizando-se a metodologia de mínimos quadrados, aplicável a números desiguais nas subclasses (Stell \& Torrie, 1980).

No confinamento (fase 2), os animais foram contidos individualmente em área revestida de cimento e coberta, provida de cochos e bebedouros individuais. Na primeira semana, de adaptação às dietas experimentais, os animais passaram a receber silagem de milho e quantidades crescentes de concentrado.

Todos os animais receberam a mesma mistura completa, constituída de $44 \%$ de silagem de milho e 56\% de concentrado na MS. O concentrado foi constituído de farelo de soja $(19,4 \%)$, fubá de milho $(74,3 \%)$, uréia $(3,0 \%)$ e $3,2 \%$ de mistura mineral contendo fosfato bicálcico, calcário, sal e microelementos minerais. A ração completa, contendo $17,6 \%$ de PB e 2,57 Mcal de EM/kg, foi calculada de acordo com as normas do AFRC (1993), de modo a permitir ganho de peso vivo diário de 1,2 kg para os animais alimentados ad libitum.

A dieta era fornecida uma vez ao dia, individualmente. As quantidades de alimento fornecidas aos animais do grupo de mantença foram ajustadas a cada 28 dias, de acordo com os pesos individuais, e, para os animais alimentados ad libitum (tratamentos controle e ganho compensatório), a quantidade foi aumentada quando necessário, mantendo-se as sobras entre 5 e $10 \%$ do total fornecido. Para determinação do consumo alimentar individual, foram registradas diariamente a quantidade de ração fornecida e as sobras. Amostras do alimento oferecido e das sobras foram coletadas diariamente, constituindo amostras compostas por animal por período de 28 dias.

No primeiro dia de confinamento, três animais de cada tratamento, um de cada bloco, escolhidos ao acaso, foram abatidos constituindo os grupos de referência, para estimativa da composição corporal e do peso corporal vazio (PCVZ) inicial dos 30 animais remanescentes. Nos dias 28, 56,84 , e 112 de confinamento, foram abatidos três animais do regime de ganho compensatório e três do regime de mantença. Nos dias 28 e 112, foram igualmente abatidos três animais do grupo controle, sempre um animal de cada bloco por tratamento. Por ocasião dos abates, os animais foram submetidos a um período de jejum de 14 horas, com acesso a água, sendo pesados imediatamente antes do abate. O abate foi feito por meio de concussão cerebral e posterior secção da veia jugular. As carcaças foram serradas ao meio e as duas meias-carcaças foram pesadas individualmente $\mathrm{e}$ mantidas em câmara fria, a $-5^{\circ} \mathrm{C}$, durante aproximadamente 18 horas.

Após o abate, foram pesados e amostrados os seguintes componentes: sangue, cabeça, pés, couro, cauda, rúmenretículo, omaso, abomaso, intestinos delgado e grosso, mesentério, gordura interna, baço, coração, fígado, pulmões, rins, língua, carne industrial, esôfago, traquéia e aparelho reprodutor. O peso corporal vazio (PCVZ) dos animais foi determinado somando-se os pesos de todos os componentes corporais. As relações entre o PCVZ e o peso vivo (PV) dos animais-referência de cada regime de alimentação foram determinados e os valores utilizados para estimativa do PCVZ inicial dos animais remanescentes. $\mathrm{O}$ PCVZ final de todos os animais foi determinado após o abate, de modo semelhante ao adotado para os animaisreferência.

Os teores de MS e PB foram determinados nas amostras dos alimentos e das sobras, segundo metodologia descrita por Silva (1990). O conteúdo de EM foi obtido a partir do conteúdo de energia digestível da ração, determinado em ensaio de digestibilidade utilizando-se o fator de conversão 0,82 (NRC, 1996).

Os resultados do consumo de matéria seca, do ganho de peso vivo, do ganho de peso corporal vazio, do ganho de carcaça e de componentes não-carcaça durante a fase de confinamento foram analisados segundo o modelo:

$$
\mathrm{Y}_{\mathrm{ijkl}}=\mu+\mathrm{T}_{\mathrm{i}}+\mathrm{B}_{\mathrm{j}}+\mathrm{P}_{\mathrm{k}}+\mathrm{TB}_{\mathrm{ij}}+\mathrm{TP}_{\mathrm{ik}}+\mathrm{E}_{\mathrm{ijkl}}
$$

em que: $\mathrm{Y}_{\mathrm{ijkl}}=$ observação referente ao animal 1, do tratamento $\mathrm{i}$, do bloco $\mathrm{j}$ e do período $\mathrm{k} ; \mu=$ média geral; $\mathrm{T}_{\mathrm{i}}=$ efeito do tratamento $i$, em que $\mathrm{i}=1$ (controle), 2 (ganho compensatório) e 3 (mantença); $B_{j}=$ efeito do bloco $j$, em que $\mathrm{j}=1$ (pesado), 2 (intermediário) e 3 (leve); $\mathrm{P}_{\mathrm{k}}=$ efeito do período $\mathrm{k}$, em que k = 1 ( 0 a 28 dias) e 2 (29 a 112 dias); $\mathrm{TB}_{\mathrm{ij}}=$ interação tratamento $\mathrm{i} \times$ bloco $\mathrm{j}$; $\mathrm{TP}_{\mathrm{ik}}=$ interação tratamento $\mathrm{i} \times$ período $\mathrm{k} ; \mathrm{E}_{\mathrm{ijkl}}=$ erro aleatório, pressuposto normalmente distribuído, com média zero e variância $\sigma^{2}$.

O mesmo modelo foi utilizado para análise dos dados de conversão alimentar, porém, foram considerados somente os grupos controle e ganho compensatório. Modelo semelhante também foi utilizado para avaliar os resultados do consumo de matéria seca, dos ganhos de peso de corpo vazio e de carcaça e do ganho total dos componentes nãocarcaça nos quatro períodos sucessivos de 28 dias, correspondentes aos abates de animais dos grupos ganho compensatório (GC) e mantença (MT). O modelo incluiu os 
efeitos dos quatro períodos, dos dois tratamentos, dos blocos e das interações tratamento $\times$ bloco e tratamento $\times$ período.

$\mathrm{Na}$ avaliação dos resultados do ganho de peso dos animais alimentados ad libitum e daqueles submetidos ao pastejo restrito, no período que precedeu o confinamento (fase 1), utilizou-se um modelo incluindo os efeitos de bloco e do nível de ingestão de forragem (ad libitum e restrito).

Os dados foram analisados por análises de variância e de regressão, utilizando-se o programa LSMLMW (Least Squares and Maximum Likelihood Mixed Model), versão PC-1 (Harvey, 1990), e as médias foram comparadas pelo teste de Student-Newman-Keuls, a 5\% de probabilidade.

\section{Resultados e Discussão}

O ganho de peso médio diário dos animais em pastejo ad libitum no período de pastejo (fase 1) foi de $0,453 \mathrm{~kg}$, superior $(\mathrm{P}<0,01)$ ao daqueles em pastejo restrito (alocados na fase 2 nos tratamentos ganho compensatório e mantença), que ganharam, em média, $0,124 \mathrm{~kg} /$ dia. Variações no peso do conteúdo do trato gastrintestinal dos animais submetidos às duas ofertas de forragem na fase 1 não puderam ser determinadas, pois não houve abate de animais no início desse período. Não foi determinado também o consumo de forragem.

O ganho de peso médio diário dos animais em pastejo ad libitum foi apenas moderado, embora a fase 1 tenha coincidido com o início do período chuvoso.

Os animais submetidos ao pastejo restrito com pressão de pastejo elevada apresentaram baixas taxas de ganho, tendo em vista o objetivo de submetê-los ao período de confinamento com peso corporal próximo ao observado no início do período de pastejo. Ryan (1990) e Laurence \& Fowler (1997) comprovaram haver correlações negativas entre os níveis de ganho durante o inverno e no período subseqüente, a pasto ou em confinamento, quando o nível nutricional é adequado. Entretanto, resultados obtidos por esses autores indicam que ganho de peso semelhante aos observado nos animais controle (pastejo ad libitum) pode não ter efeito negativo sobre o ganho na fase posterior caso os animais recebam alimentação adequada.

Os valores médios de consumo de MS durante o período de confinamento (fase 2) dos animais dos tratamentos controle, ganho compensatório e mantença podem ser observados na Tabela 1. A análise de variância comprovou haver efeito da interação $(\mathrm{P}<0,05)$ tratamento $\times$ período para o consumo total diário de MS (CMSD), o consumo de
MS por $100 \mathrm{~kg}$ de PV (CPV), o consumo por $100 \mathrm{~kg}$ de peso de corpo vazio (CPVZ) e o consumo por unidade de tamanho metabólico (CUTM). O consumo médio total diário de MS dos animais nos tratamentos em que a dieta foi fornecida ad libitum (controle e ganho compensatório) foi maior $(\mathrm{P}<0,05)$ no período de 29 a 112 dias em comparação ao período de 1 a 28 dias, refletindo o aumento do peso corporal dos animais. Entretanto, quando expresso como proporção do peso do animal em CPV, CPVZ ou CUTM, houve redução do consumo desses animais no segundo período $(\mathrm{P}<0,05)$.

O maior consumo alimentar relativo ao peso nos primeiros 28 dias de confinamento nos animais alimentados ad libitum pode ser, em parte, uma resposta ao período de ganho compensatório e está de acordo com os relatos de Ryan (1990), Hogg (1991) e Sainz (1998). Os animais que tiveram livre acesso à pastagem no início da estação chuvosa tiveram naquele período ganhos de peso apenas moderados $(0,453 \mathrm{~kg} / \mathrm{dia})$ e, portanto, apresentavam condições para o ganho compensatório, que normalmente está associado a aumento do consumo alimentar. Além disso, conforme salientado por Sainz (1998), quando a restrição alimentar ocorre por ingestão de dieta de baixa qualidade e não por baixo nível de oferta de dieta de alta qualidade, não ocorre redução do tamanho do trato gastrintestinal, especialmente do rúmen-retículo. Desse modo, a elevação do consumo alimentar quando o animal tem acesso ad libitum a alimento de boa qualidade tende a ser mais rápida.

Com o prolongamento do período de confinamento, a tendência normal é de redução do consumo alimentar em relação ao peso do animal, como resultado do acúmulo de gordura corporal, associado à limitação, a longo prazo, do consumo em bovinos de corte (NRC, 1996).

Nos dois períodos, os animais dos grupos controle e ganho compensatório (animais alimentados ad libitum) não diferiram $(\mathrm{P}>0,05)$ quanto ao consumo total diário ou em porcentagem do peso vivo, do peso de corpo vazio ou por unidade de tamanho metabólico. Nos animais do regime de mantença, o consumo total diário expresso em relação ao peso vivo, ao peso do corpo vazio ou ao tamanho metabólico permaneceu inalterado nos dois períodos ( 1 a 28 e 29 a 112 dias), de acordo com o estabelecido, mantendo-se menor que nos animais em ganho contínuo e em ganho compensatório $(\mathrm{P}<0,05)$.

A regressão do consumo total diário de matéria seca (CMSD) em função do tempo de confinamento comprovou aumento linear $(\mathrm{P}<0,01)$ do consumo, descrito pelas equação: $\mathrm{CMSD}=7,1452+0,01959 \mathrm{X}\left(\mathrm{r}^{2}=0,93\right)$, para os animais 
Tabela 1 - Consumo total diário de matéria seca (CMSD), consumo de MS em porcentagem do peso vivo (\% PV), em porcentagem do peso de corpo vazio (\% PVZ) e por unidade de tamanho metabólico (CUTM) para os tratamentos controle, ganho compensatório e mantença nos períodos de 1 a 28 dias e de 29 a 112 dias de confinamento

Table 1 - Least square means and standard errors for total daily intake of DM (DMI), DM intake as percentage of body weight (\%BW) and empty body weight (\%EBWT), and per unit of metabolic weight $\left(w^{0.75}\right)$ for control, compensatory growth, and maintenance treatments at different periods of feedlot

\begin{tabular}{|c|c|c|c|}
\hline $\begin{array}{l}\text { Período de confinamento } \\
\text { Period of feedlot }\end{array}$ & $\begin{array}{l}\text { Controle } \\
\text { Control }\end{array}$ & $\begin{array}{l}\text { Ganho compensatório } \\
\text { Compensatory growth }\end{array}$ & $\begin{array}{l}\text { Mantença } \\
\text { Maintenance }\end{array}$ \\
\hline & \multicolumn{3}{|c|}{$\begin{array}{c}\text { CMSD }(\mathrm{kg}) \\
\quad D M I\end{array}$} \\
\hline $\begin{array}{l}1 \text { a } 28 \text { dias (from day } 1 \text { to } 28 \text { ) } \\
29 \text { a } 112 \text { dias (from day } 29 \text { to } 112 \text { ) }\end{array}$ & $\begin{array}{l}7,56 \pm 0,15 \mathrm{Ba} \\
8,69 \pm 0,21 \mathrm{Aa}\end{array}$ & $\begin{array}{l}7,28 \pm 0,10 \mathrm{Ba} \\
8,38 \pm 0,12 \mathrm{Aa}\end{array}$ & $\begin{array}{l}2,61 \pm 0,10 \mathrm{Ab} \\
2,54 \pm 0,12 \mathrm{Ab}\end{array}$ \\
\hline 29 a 112 dias (from day 29 to 112 ) & \multicolumn{3}{|c|}{$\begin{array}{ll}\% & \mathrm{PV} \\
\% & B W\end{array}$} \\
\hline \multirow[t]{2}{*}{29 a 112 dias (from day 29 to 112 ) } & $\begin{array}{l}3,04 \pm 0,07 \mathrm{Aa} \\
2,67 \pm 0,09 \mathrm{Ba}\end{array}$ & $\begin{array}{l}3,11 \pm 0,05 \mathrm{Aa} \\
2,67 \pm 0,06 \mathrm{Ba}\end{array}$ & $\begin{array}{l}1,27 \pm 0,05 \mathrm{Ab} \\
1,18 \pm 0,06 \mathrm{Ab}\end{array}$ \\
\hline & \multicolumn{3}{|c|}{$\begin{array}{c}\% \mathrm{PVZ} \\
\% \quad E B W T\end{array}$} \\
\hline $\begin{array}{l}1 \text { a } 28 \text { dias (from day } 1 \text { to } 28 \text { ) } \\
29 \text { a } 112 \text { dias (from day } 29 \text { to } 112 \text { ) }\end{array}$ & $\begin{array}{l}3,72 \pm 0,08 \mathrm{Aa} \\
3,05 \pm 0,12 \mathrm{Ba}\end{array}$ & $\begin{array}{l}3,84 \pm 0,06 \mathrm{Aa} \\
3,07 \pm 0,07 \mathrm{Ba}\end{array}$ & $\begin{array}{l}1,57 \pm 0,06 \mathrm{Ab} \\
1,38 \pm 0,07 \mathrm{Ab}\end{array}$ \\
\hline 29 a 112 dias (from day 29 to 112 ) & \multicolumn{3}{|c|}{$\begin{array}{c}\text { CUTM }(\mathrm{g}) \\
W^{0.75}\end{array}$} \\
\hline $\begin{array}{l}1 \text { a } 28 \text { dias (from day } 1 \text { to } 28 \text { ) } \\
29 \text { a } 112 \text { dias (from day } 29 \text { to } 112 \text { ) }\end{array}$ & $\begin{array}{l}119,43 \pm 2,10 \mathrm{Aa} \\
112,94 \pm 2,80 \mathrm{Ba}\end{array}$ & $\begin{array}{l}121,27 \pm 1,50 \mathrm{Aa} \\
112,50 \pm 1,70 \mathrm{Ba}\end{array}$ & $\begin{array}{l}47,89 \pm 1,50 \mathrm{Ab} \\
45,23 \pm 1,70 \mathrm{Ab}\end{array}$ \\
\hline
\end{tabular}

Médias seguidas, em cada linha (coluna), de mesma letra minúscula (maiúscula) não diferem $(P>0,05)$ pelo teste Student Newman-Keuls. Means in each row (column) followed by the same small (capital) letter do not differ $(P>0.05)$ by Newman-Keuls test.

dos grupos controle e ganho compensatório, e redução linear: $\mathrm{CMSD}=2,6243-0,00114 \mathrm{X}\left(\mathrm{r}^{2}=0,93\right)$ para animais em mantença. Para o consumo expresso em CPV, CPVZ e CUTM, houve reduções lineares $(\mathrm{P}<0,01)$ do consumo ao longo do período de confinamento, descritas pelas equações: $\mathrm{CPV}=3,1689-0,00698 \mathrm{X}\left(\mathrm{r}^{2}=0,96\right)$, para animais controle e de ganho compensatório; $\mathrm{CPV}=1,2861$ $0,00145 \mathrm{X}\left(\mathrm{r}^{2}=0,96\right)$, para animais em mantença; $\mathrm{CPVZ}=$ $3,8887-0,01181 \mathrm{X}\left(\mathrm{r}^{2}=0,96\right)$, para os animais controle; $\mathrm{CPVZ}=4,0309-0,01358 \mathrm{X}\left(\mathrm{r}^{2}=0,96\right)$ para os animais de ganho compensatório; $\mathrm{CPVZ}=1,6156-0,00332 \mathrm{X}\left(\mathrm{r}^{2}=\right.$ $0,96)$, para os animais em mantença; CUTM $=122,2261-$ $0,13389 \mathrm{X}\left(\mathrm{r}^{2}=0,98\right)$, para os animais controle e de ganho compensatório; e CUTM = 48,5415-0,04659X $\left(\mathrm{r}^{2}=0,98\right)$, para os animais em mantença, sendo $\mathrm{X}$ igual ao número de dias em confinamento.

Nos grupos ganho compensatório e mantença, nos quais se fez abate a cada 28 dias, permitindo estimar as variações do peso de corpo vazio nesses intervalos, foram avaliadas as mudanças no consumo nos períodos sucessivos de 28 dias. A análise estatística revelou interação $(\mathrm{P}<0,05)$ tratamento $\times$ período para CMSD, CPV, CPVZ e CUTM (Tabela 2).

No grupo ganho compensatório, o consumo médio diário de MS tendeu a aumentar do primeiro para o quarto período de confinamento, como conseqüência do aumento do peso corporal dos animais, que foi menor no primeiro período em comparação ao segundo e ao terceiro período $(\mathrm{P}<0,05)$. Nesses períodos, o consumo foi menor que no quarto período $(\mathrm{P}<0,05)$. Quando expresso em porcentagem do peso corporal (CPV e CPVZ), o consumo no regime de ganho compensatório no primeiro período foi maior que no segundo período $(\mathrm{P}<0,05)$, quando foi mais elevado que nos dois últimos períodos $(\mathrm{P}<0,05)$, nos quais não diferiu $(\mathrm{P}>0,05)$ significativamente.

Estes resultados indicam que o aumento do consumo em animais em ganho compensatório (Ryan, 1990; Hogg, 1991; Sainz, 1998) foi mais nítido nos primeiros 28 dias de confinamento, permanecendo elevado no período seguinte e decrescendo para um nível mais baixo após 56 dias de realimentação. O aumento do consumo nos animais após período de restrição nutricional tem sido apontado como fator para o maior ganho de peso nesses animais (Ryan, 1990; Hogg, 1991).

A manutenção do consumo em nível mais elevado nos animais do grupo ganho compensatório (Tabela 2) durante os primeiros 56 dias pode ser constatada de forma mais nítida quando observado o consumo por unidade tamanho metabólico (CUTM), sendo observados consumos semelhantes nos dois primeiros períodos $(\mathrm{P}>0,05)$, superiores 
Tabela 2 - Consumo total diário de MS (CMSD), consumo de MS em porcentagem do peso vivo (\% PV), em porcentagem do peso de corpo vazio (\% PVZ) e por unidade de tamanho metabólico (CUTM) nos animais dos grupos ganho compensatório e mantença nos períodos de 1 a 28 , de 29 a 56, de 57 a 84 e de 85 a 112 dias de confinamento

Table 2 - Least square means and standard errors for total daily intake of DM (DMI), DM intake as percentage of body weight (\%BW) and empty body weight $(\% E B W T)$, and per unit of metabolic weight $\left(W^{0.75}\right)$ for compensatory growth and maintenance treatments at different periods of feedlot

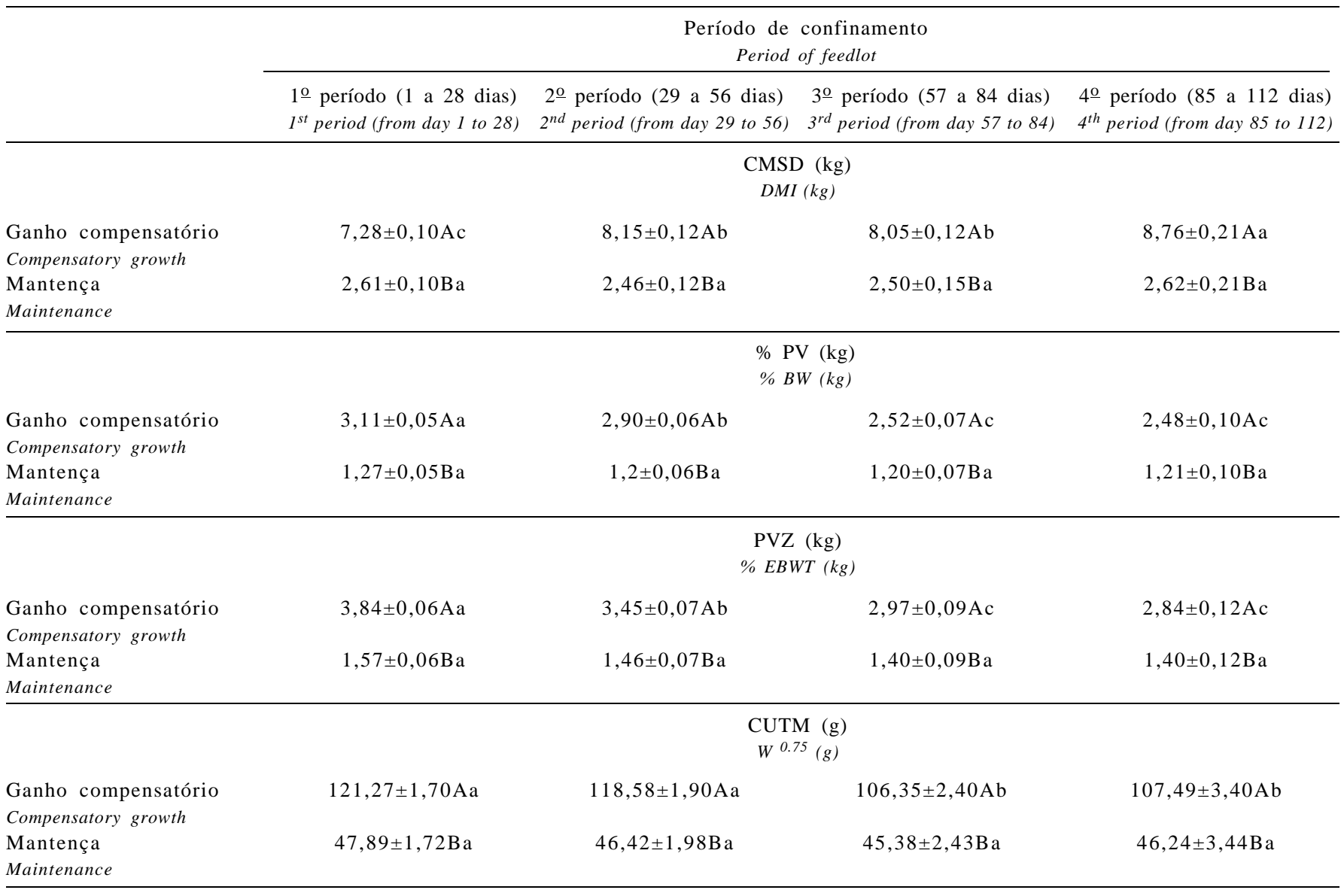

Médias seguidas, em cada linha (coluna), de mesma letra minúscula (maiúscula) não diferem $(P>0,05)$ pelo teste Student Newman-Keuls.

Means in each row (column) followed by the same small (capital) letter do not differ $(P>0.05)$ by Newman-Keuls test.

aos do terceiro e quarto períodos $(\mathrm{P}<0,05)$, nos quais não diferiu significativamente $(\mathrm{P}>0,05)$.

Os ganhos médios diários de peso vivo (GPV), de peso de corpo vazio (GPVZ), do peso da carcaça (GCAR) e do peso dos componentes não-carcaça (GNCAR) nos períodos de 1 a 28 dias e de 29 a 112 dias de confinamento são apresentados na Tabela 3. Verificou-se efeito de interação tratamento $\times$ período $(\mathrm{P}<0,05)$ para GPV e GNCAR.

Quando considerado o GPV, verificou-se nos primeiros 28 dias maior ganho diário $(\mathrm{P}<0,05)$ nos animais do grupo ganho compensatório (submetidos na fase 1 ao pastejo restrito) em comparação aos do grupo controle. No período de 29 a 112 dias, não houve diferença entre os grupos (P>0,05).

Nos três grupos, os valores de ganho de PCVZ (peso de tecidos corporais livres da digesta), nos primeiros 28 dias, foram mais elevados que os de ganho de peso vivo. Este resultado indica que, nos primeiros 28 dias, depois que os animais deixaram de se alimentar em pastagem (mais rico em fibra) e passaram a ingerir dieta com $56 \%$ de concentrado, houve redução do conteúdo de digesta do trato gastrintestinal (TGI). Essa redução da digesta entre as pesagens realizadas nos dias 1 e 28 de confinamento não permitiu que o ganho de peso vivo aferisse corretamente o aumento ocorrido nos tecidos corporais no período. Evidencia que o ganho de PCVZ, por não ser influenciado as flutuações do conteúdo de digesta do TGI, indica de forma mais adequada as mudanças no peso dos tecidos corporais.

Os valores mais elevados de ganho de peso corporal obtidos nos animais em ganho compensatório, em comparação aos do grupo controle, no período de 1 a 28 dias refletem principalmente o maior ganho de peso $(\mathrm{P}<0,05)$ dos componentes não-carcaça (GNCAR) nos animais em ganho compensatório, visto que os ganhos de carcaça nesses dois grupos foram semelhantes. Corroborando os resultados deste trabalho, Carstens et al. (1991) não observaram diferenças na taxa de crescimento alométrica dos componentes químicos da carcaça entre animais em ganho compensatório 
Tabela 3 - Ganhos diários de peso vivo (GPV), de corpo vazio (GPVZ), de carcaça (GCAR) e dos componentes não-carcaça (GNCAR) nos animais dos grupos controle, ganho compensatório e mantença nos períodos de 1 a 28 dias e de 29 a 112 dias de confinamento

Table 3 - $\quad$ Least square means and standard errors for daily gains of body weight (BWG), empty body weight (EBWTG), carcass weight (CWTG) and non carcass components weight (NCWTG) for control, compensatory growth and maintenance treatments at different periods of feedlot

\begin{tabular}{|c|c|c|c|c|}
\hline $\begin{array}{l}\text { Período de confinamento } \\
\text { Period of feedlot }\end{array}$ & $\begin{array}{l}\text { Controle } \\
\text { Control }\end{array}$ & $\begin{array}{c}\text { Ganho compensatório } \\
\text { Compensatory growth }\end{array}$ & $\begin{array}{l}\text { Mantença } \\
\text { Maintenance }\end{array}$ & $\begin{array}{l}\text { Média } \\
\text { Mean }\end{array}$ \\
\hline & \multicolumn{4}{|c|}{$\begin{array}{l}\text { GPV } \\
\text { (kg/dia) } \\
B W G(\mathrm{~kg} / \text { day })\end{array}$} \\
\hline $\begin{array}{l}1 \text { a } 28 \text { dias } \\
\text { From day } 1 \text { to } 28\end{array}$ & $0,72 \pm 0,09 \mathrm{Bb}$ & $1,27 \pm 0,07 \mathrm{Aa}$ & $-0,42 \pm 0,07 \mathrm{Bc}$ & $0,53 \pm 0,04$ \\
\hline $\begin{array}{l}29 \text { a } 112 \text { dias } \\
\text { From day } 29 \text { to } 112\end{array}$ & $1,20 \pm 0,13 \mathrm{Aa}$ & $1,18 \pm 0,13 \mathrm{Aa}$ & $0,09 \pm 0,13 \mathrm{Ab}$ & $0,82 \pm 0,08$ \\
\hline $\begin{array}{l}\text { Média } \\
\text { Average }\end{array}$ & $0,96 \pm 0,08$ & $1,23 \pm 0,07$ & $-0,17 \pm 0,07$ & \\
\hline
\end{tabular}

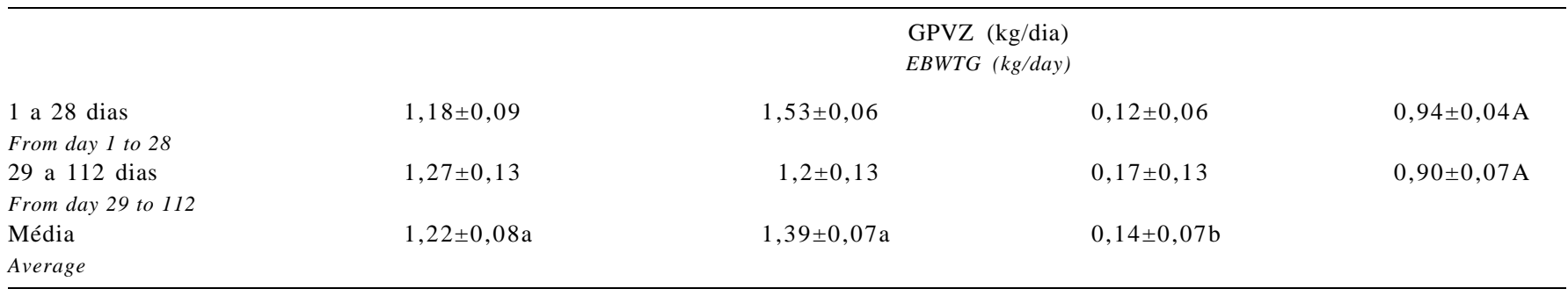

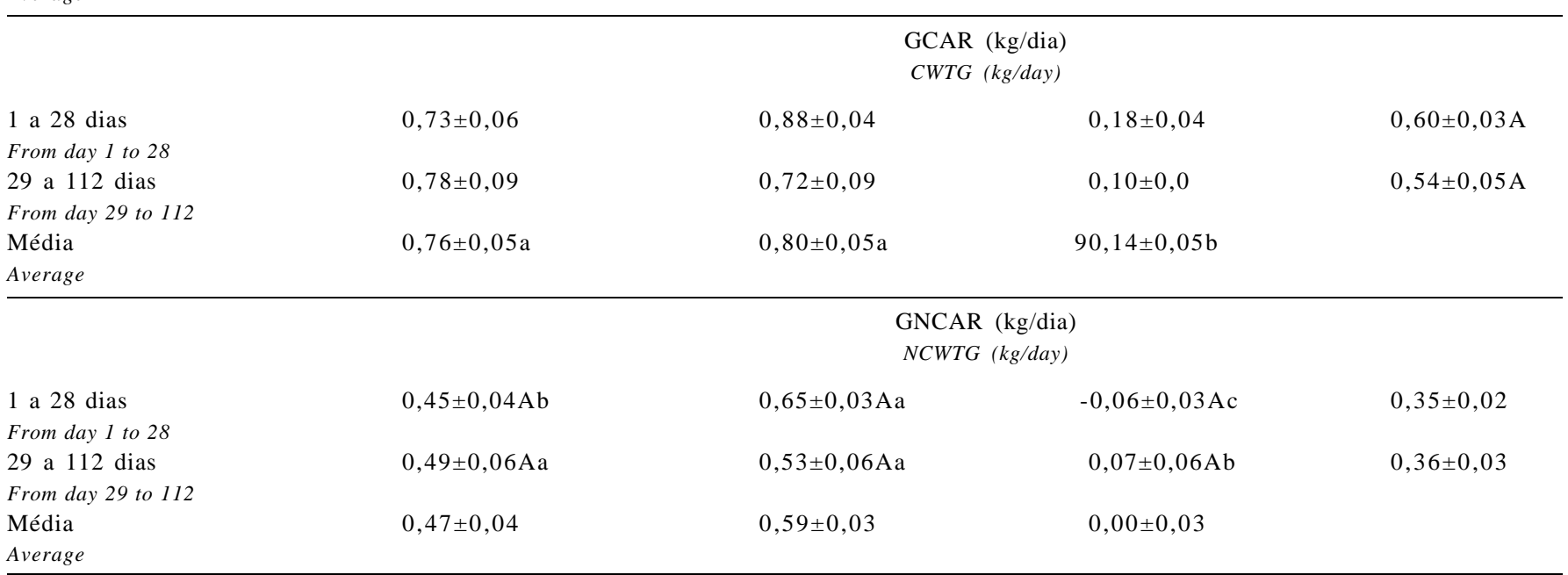

Médias seguidas, em cada linha (coluna), pela mesma letra minúscula (maiúscula) não diferem $(P>0,05)$ pelos testes $F$ e Student Newman-Keuls. Means in each row (column) followed by the same small (capital) letter do not differ $(P>0.05)$ by Newman-Keuls test or F test.

e em ganho contínuo. Entretanto, as taxas de deposição de proteína e água nos componentes não-carcaça foram maiores nos animais em ganho compensatório.

Hogg (1991) enfatizou que, durante o crescimento compensatório, grande parte das alterações no peso do animal resulta da recuperação da atividade metabólica do fígado e do intestino delgado e do aumento de peso desses órgãos. Neste trabalho, o maior ganho dos componentes não-carcaça nos primeiros 28 dias de confinamento nos animais em ganho compensatório indicou recuperação do peso dos órgãos internos na fase inicial de confinamento.

Apesar de a maior parte da diferença no ganho de peso corporal entre os grupos ganho compensatório e controle ser explicada pelo ganho dos componentes não-carcaça, o ganho de peso da carcaça representou a maior parte do ganho de peso dos animais desses dois grupos durante a fase de confinamento.

Quando analisados os ganhos médios diários em todo o período de confinamento (1 a 112 dias), os grupos controle e ganho compensatório $(\mathrm{P}>0,05)$ não diferiram quanto aos ganhos de peso: GPV (1,08 e 1,20 kg/dia); GPVZ (1,25 e 1,32 kg/dia); GCAR (0,77 e 0,76 kg/dia); e GNCAR $(0,48$ e $0,56 \mathrm{~kg} / \mathrm{dia})$. Os animais desses grupos superaram os do grupo mantença $(\mathrm{P}<0,05)$ em todos os ganhos de peso avaliados.

Nos grupos ganho compensatório e mantença, foi possível avaliar os ganhos de PCVZ, de peso de carcaça e de 
peso dos componentes não-carcaça, pois os abates foram realizados nos intervalos estabelecidos (28 dias). Essa análise, especialmente para os animais em ganho compensatório, é importante por permitir verificar a ocorrência de possível variação na velocidade dos ganhos nos subperíodos intermediários. A análise de variância indicou efeito do regime de alimentação $(\mathrm{P}<0,01)$ e da interação tratamento $\times$ subperíodo $(\mathrm{P}<0,05)$ para todos os ganhos de peso considerados (Tabela 4).

O ganho de peso de corpo vazio dos animais do tratamento ganho compensatório nos quatro períodos sucessivos de 28 dias foi maior $(\mathrm{P}<0,05)$ no primeiro período e não diferiu nos três últimos subperíodos $(\mathrm{P}>0,05)$.

Ryan (1990) e Hogg (1991) relataram que, após um período de restrição alimentar, ao proporcionar um nível nutricional adequado, ocorre normalmente ganho de peso corporal mais acelerado, em decorrência do rápido aumento inicial do tamanho dos órgãos internos metabolicamente ativos e da maior retenção de água nas fibras musculares que antecede a deposição mais intensa de proteína nos músculos. Como salientaram esses autores, o tempo em que a taxa de peso se mantém mais acelerada depende de diversos fatores, entre eles, a severidade e a duração do período de restrição alimentar.
O ganho de peso corporal $(\mathrm{P}<0,05)$ mais acelerado ocorreu durante os primeiros 28 dias, apesar de ter sido numericamente mais elevado no segundo, em comparação ao terceiro período, sem que a diferença fosse significativa. O ganho de peso diário dos componentes não-carcaça nos animais do grupo ganho compensatório foi de $0,65 \mathrm{~kg}$ no primeiro período, equivalente a $42,5 \%$ do ganho total de PCVZ. Essa porcentagem diminuiu para 37,3 e 36,4\% no segundo e terceiro períodos, respectivamente, e aumentou para $51,7 \%$ do PCVZ no quarto período. A maior participação dos componentes não-carcaça $(\mathrm{P}<0,05)$ no primeiro em relação ao terceiro e quarto períodos pode ser atribuída ao crescimento intenso dos órgãos na fase 1nicial, como verificado por Ryan (1990), Hogg (1991) e Nicol \& Kitessa (1995). Por outro lado, o aumento do peso e da participação dos componentes não-carcaça no GPVZ no quarto período pode ser atribuído, pelo menos em parte, ao maior acúmulo de gordura visceral em detrimento da gordura subcutânea, o que ocorre em maior proporção em animais em ganho compensatório (Sainz, 1998).

O ganho de peso da carcaça nos animais em ganho compensatório tendeu a decrescer em cada período sucessivo de confinamento e foi mais elevado no primeiro em comparação ao quarto período $(\mathrm{P}<0,05)$. Nos animais em

Tabela 4 - Ganhos diários dos pesos de corpo vazio (GPVZ), de carcaça (GCAR) e dos componentes não-carcaça (GNCAR) nos animais dos grupos ganho compensatório e mantença nos períodos de 1 a 28, 29 a 56,57 a 84 e 85 a 112 dias de confinamento

Table 4 - Least square means and standard errors for daily gains of empty body weight (EBWTG), carcass weight (CWTG) and non carcass components weight (NCWTG) for compensatory growth and maintenance treatments at different periods of feedlot

Período de confinamento

Period of feedlot

\begin{tabular}{|c|c|c|c|c|}
\hline & & & & \\
\hline & $\begin{array}{l}1 \text { o período ( } 1 \text { a } 28 \text { dias) } \\
1^{\text {st }} \text { period (from day } 1 \text { to } 28 \text { ) }\end{array}$ & $\begin{array}{l}2^{\mathrm{o}} \text { período ( } 29 \text { a } 56 \text { dias) } \\
\left.2^{\text {nd }} \text { period (from day } 29 \text { to } 56\right)\end{array}$ & $\begin{array}{l}3 \text { o período ( } 57 \text { a } 84 \text { dias }) \\
\left.3^{\text {rd }} \text { period (from day } 57 \text { to } 84\right)\end{array}$ & $\begin{array}{l}4^{\mathrm{o}} \text { período ( } 85 \text { a } 112 \text { dias) } \\
4^{\text {th }} \text { period (from day } 85 \text { to } 112 \text { ) }\end{array}$ \\
\hline & \multicolumn{4}{|c|}{$\begin{array}{l}\text { GPVZ (kg/dia) } \\
\text { EBWTG (kg/day) }\end{array}$} \\
\hline $\begin{array}{l}\text { Ganho compensatório } \\
\text { Compensatory growth }\end{array}$ & $1,53 \pm 0,07 \mathrm{Aa}$ & $1,26 \pm 0,09 \mathrm{Ab}$ & $1,10 \pm 0,10 \mathrm{Ab}$ & $1,20 \pm 0,11 \mathrm{Ab}$ \\
\hline $\begin{array}{l}\text { Mantença } \\
\text { Maintenance }\end{array}$ & $0,12 \pm 0,07 \mathrm{Ba}$ & $0,12 \pm 0,09 \mathrm{Ba}$ & $0,11 \pm 0,10 \mathrm{Ba}$ & $0,30 \pm 0,11 \mathrm{Ba}$ \\
\hline
\end{tabular}

\begin{tabular}{|c|c|c|c|c|}
\hline \multirow[b]{2}{*}{$\begin{array}{l}\text { Ganho compensatório } \\
\text { Compensatory growth }\end{array}$} & \multicolumn{4}{|c|}{$\begin{array}{c}\text { GCAR }(\mathrm{kg} / \mathrm{dia}) \\
C W T G(k g / d a y)\end{array}$} \\
\hline & $0,88 \pm 0,05 \mathrm{Aa}$ & $0,80 \pm 0,06 \mathrm{Aab}$ & $0,70 \pm 0,07 \mathrm{Aab}$ & $0,57 \pm 0,10 \mathrm{Ab}$ \\
\hline $\begin{array}{l}\text { Mantença } \\
\text { Maintenance }\end{array}$ & $0,18 \pm 0,05 \mathrm{Ba}$ & $0,00 \pm 0,06 \mathrm{~B} \mathrm{a}$ & $0,11 \pm 0,07 \mathrm{Ba}$ & $0,22 \pm 0,10 \mathrm{Ba}$ \\
\hline
\end{tabular}

GNCAR (kg/dia)

NCWTG (kg/day)

Ganho compensatório

Compensatory growth

Mantença

Maintenance
$0,65 \pm 0,04 \mathrm{Aa}$

$-0,06 \pm 0,04 \mathrm{Bb}$
$0,47 \pm 0,05 \mathrm{Ab}$

$0,12 \pm 0,05 \mathrm{Ba}$
$0,40 \pm 0,06 \mathrm{Ab}$

$0,00 \pm 0,06 \mathrm{Bab}$
$0,62 \pm 0,08 \mathrm{Aab}$

$0,08 \pm 0,08 \mathrm{Bab}$

Médias seguidas, em cada linha (coluna), pela mesma letra minúscula (maiúscula) não diferem $(P>0,05)$ pelo teste de Student Newman-Keuls. Means in each row (column) followed by the same small (capital) letter do not differ $(P>0.05)$ by Newman-Keuls test. 
mantença, os ganhos de peso expressos em GPV, GPVZ, GCAR e GNCC foram baixos em todos os períodos, menores que os obtidos nos animais em ganho compensatório $(\mathrm{P}<0,05)$, como consequiência da oferta limitada de alimentos no grupo mantença.

A análise de variância para os conteúdos de digesta no trato gastrintestinal referentes aos animais dos três tratamentos abatidos no início e nos dias 28 e 112 de confinamento, expressos como porcentagem do peso vivo (DIGPV) e como porcentagem do peso de corpo vazio (DIGPZ), comprovou não haver interação $(\mathrm{P}>0,05)$ tratamentos $\times$ idade de abate e, portanto, seus efeitos foram avaliados independentemente, como demonstrado na Tabela 5.

Houve redução $(\mathrm{P}<0,05)$ da participação percentual média de digesta no peso vivo e no peso de corpo vazio ao longo do período de confinamento (efeito médio de dia de abate). Entretanto, não houve diferença entre os três regimes de alimentação $(\mathrm{P}>0,05)$ quanto ao valor percentual médio de digesta nos três períodos (efeito médio de tratamento).

Embora a digesta representasse percentual semelhante nos animais dos grupos controle e ganho compensatório no início do período de confinamento (em torno de $21 \%$ ), os animais controle, com maior peso vivo (média de $249,0 \mathrm{~kg}$ ) em comparação aos do ganho compensatório (média de $214,8 \mathrm{~kg})$, apresentaram maior peso de digesta $(52,4 \mathrm{vs}$ $46,5 \mathrm{~kg}$ ). Aos 28 dias de confinamento, os pesos médios aproximados da digesta dos animais dos dois grupos foram, respectivamente, 40,0 e 39,6 kg, ou seja, houve redução de 12,4 e $6,9 \mathrm{~kg}$ de digesta em 28 dias de confinamento, ou de $0,44 \mathrm{e} 0,25 \mathrm{~kg} / \mathrm{dia}$, nos animais dos grupos controle e ganho compensatório, respectivamente. Esta redução no peso da digesta explica as diferenças entre o ganho de PCVZ e o ganho de PV nesses dois grupos no período de 1 a 28 dias de confinamento. Comprova ainda a importância de se conhecer o PCVZ quando se pretende medir as diferenças de peso corporal de bovinos, especialmente quando ocorre mudança no regime alimentar, uma vez que o PCVZ, ao contrário do peso vivo, não é influenciado pelas variações do conteúdo de digesta do TGI.

Os animais do regime de mantença, apesar da menor ingestão diária de alimento, em comparação aos dos outros grupos, tiveram porcentagens semelhantes de digesta em relação ao peso corporal $(\mathrm{P}>0,05)$. Esta constatação reforça a afirmativa da ARC (1980) de que o nível de ingestão de alimento tem pouca influência sobre o conteúdo do TGI de ruminantes. Entretanto, Sainz (1998) observou que os conteúdos no trato digestivo de animais confinados alimentados com dietas ad libitum foram menores que os

Tabela 5 - Pesos de digesta em porcentagem do PV (DIGPV) e em porcentagem do peso corporal vazio (DIGPZ) dos animais dos grupos controle, ganho compensatório e mantença abatidos no início e aos 28 e 112 dias de confinamento

Table 5 - Least square means and standard errors for weight of digesta, as percentage of BW (\%BW) or empty BW (\%EBWT) from animals of control, compensatory growth and maintenance treatments slaughtered at beginning and at days 28 and 112 of feedlot

\begin{tabular}{lccc}
\hline $\begin{array}{l}\text { Abate } \\
\text { Slaughter }\end{array}$ & $\begin{array}{c}\text { Controle } \\
\text { Control }\end{array}$ & $\begin{array}{c}\text { Ganho compensatório } \\
\text { Compensatory growth }\end{array}$ & $\begin{array}{c}\text { Mantença } \\
\text { Maintenance }\end{array}$ \\
\hline
\end{tabular}

\begin{tabular}{|c|c|c|c|c|}
\hline \multirow[b]{2}{*}{ Inicial } & \multicolumn{4}{|c|}{$\begin{array}{c}\text { DIGPV (\%) } \\
\% B W\end{array}$} \\
\hline & $21,04 \pm 1,04$ & $21,64 \pm 1,04$ & $21,64 \pm 1,04$ & $21,44 \pm 0,60 \mathrm{~A}$ \\
\hline Initial & & & & \\
\hline $\begin{array}{l}28 \text { dias } \\
\text { Dav } 28\end{array}$ & $14,87 \pm 1,04$ & $15,84 \pm 1,04$ & $15,31 \pm 1,04$ & $15,34 \pm 0,60 \mathrm{~B}$ \\
\hline 112 dias & $9,69 \pm 1,04$ & $9,69 \pm 1,04$ & $12,39 \pm 1,04$ & $10,59 \pm 0,60 \mathrm{C}$ \\
\hline Day 112 & & & & \\
\hline Média & $15,20 \pm 0,60 \mathrm{a}$ & $15,73 \pm 0,60 \mathrm{a}$ & $16,45 \pm 0,60 \mathrm{a}$ & \\
\hline
\end{tabular}

Average

$$
\begin{gathered}
\text { DIGPZ }(\%) \\
\% E B W T
\end{gathered}
$$

\begin{tabular}{|c|c|c|c|c|}
\hline \multirow{2}{*}{\multicolumn{5}{|c|}{$\begin{array}{l}\text { Inicial } \\
\text { Initial }\end{array}$}} \\
\hline & & & & \\
\hline 28 dias & $17,64 \pm 1,43$ & $18,94 \pm 1,43$ & $18,25 \pm 1,43$ & $18,28 \pm 0,82 \mathrm{~B}$ \\
\hline \multicolumn{5}{|l|}{ Day 28} \\
\hline 112 dias & $10,82 \pm 1,43$ & $10,84 \pm 1,43$ & $14,17 \pm 1,43$ & $11,94 \pm 0,82$ \\
\hline \multicolumn{5}{|l|}{ Day 112} \\
\hline Média & $18,43 \pm 0,82 \mathrm{a}$ & $19,23 \pm 0,82 \mathrm{a}$ & $20,11 \pm 0,82 \mathrm{a}$ & \\
\hline
\end{tabular}


daqueles com consumo limitado a $70 \%$ do consumo ad libitum. $\mathrm{O}$ autor atribuiu esses resultados ao menor fluxo da digesta nos animais com consumo limitado.

A redução no conteúdo de digesta do TGI, mesmo nos animais do grupo ganho compensatório, a partir de quando entraram em confinamento, pode ser atribuída à mudança brusca na natureza da dieta, visto que, ao saírem da pastagem, mudaram de um regime alimentar em que o controle de ingestão do alimento ocorria basicamente pelo mecanismo de distensão ruminal para outro com dieta contendo $56 \%$ de concentrado, no qual o consumo passou a ser regulado basicamente por mecanismos quimiostáticos. Revisão do ARC (1980) indica que a adição de concentrados à forragem reduz, quase sempre, o volume do TGI, com reduções maiores para volumosos que proporcionam grande enchimento.

Quando a restrição alimentar ocorre por limitação da quantidade de uma dieta de alta qualidade (restrição quantitativa), resultados opostos aos deste estudo têm sido relatados. Neste caso, há relatos de elevação do conteúdo de digesta após a restrição, de modo que esse aumento pode explicar porção significativa do ganho de peso inicial (Ryan, 1990; Hogg, 1991; NRC, 1996).

Por outro lado, Yambayamba et al. (1996), avaliando novilhas de corte, não observaram influência do enchimento do TGI no ganho de peso e concluíram que o crescimento compensatório resultou da recuperação de tecidos corporais e de órgãos, como o fígado e o trato gastrintestinal. A avaliação conjunta dos resultados deste trabalho e dos obtidos por esses autores comprova que o aumento do peso do conteúdo do TGI durante o período de realimentação após período de restrição alimentar depende da natureza das dietas utilizadas nos dois períodos.
Não se pode generalizar o conceito de que o aumento do conteúdo do TGI é responsável por porção considerável do ganho compensatório.

$\mathrm{Na}$ avaliação da conversão alimentar na fase de confinamento, foram considerados apenas os animais dos tratamentos controle e ganho compensatório, que receberam alimento ad libitum. A conversão alimentar foi expressa em kg de MS da dieta para $1 \mathrm{~kg}$ de PCVZ ganho, o que elimina a influência de variações do conteúdo do TGI. Foram considerados os períodos de confinamento de 1 a 28 dias e de 29 a 112 dias utilizando-se as informações referentes aos animais abatidos nos dois períodos.

Apesar da tendência de interação tratamento $\times$ período $(\mathrm{P}<0,11)$, não foi atingido o nível de significância adotado no trabalho $(\mathrm{P}>0,05) \mathrm{e}$, por isso, os efeitos de tratamento e período foram considerados independentes na comparação das médias (Tabela 6). Considerando os animais dos dois tratamentos em cada período (efeito médio do período), constata-se que a conversão alimentar foi melhor $(\mathrm{P}<0,05)$ no primeiro período $(5,67 \pm 0,28)$ em comparação ao segundo $(6,89 \pm 0,32)$, não havendo diferença entre os regimes de alimentação $(\mathrm{P}>0,05)$ se considerados em conjunto os dois períodos de confinamento (efeito médio de tratamento). Como não houve efeito da interação tratamento $\times$ período ( $\mathrm{P}>0,05)$, não é estatisticamente apropriado buscar diferenças entre os regimes de alimentação nos períodos, entretanto, fica evidente que a alta eficiência de utilização da energia da dieta pelos animais do grupo ganho compensatório nos primeiros 28 dias de confinamento, comprova-

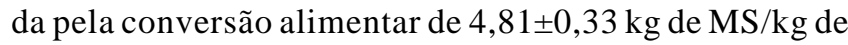
ganho de peso de corpo vazio. Aparentemente, esse resultado foi a causa da tendência observada $(\mathrm{P}<0,11)$, de interação tratamento $\times$ período.

Tabela 6 - Conversão alimentar em $\mathrm{kg}$ de MS por kg de ganho de peso de corpo vazio (GPCZ) nos animais dos grupos controle e ganho compensatório nos períodos de 1 a 28 e de 29 a 112 dias de confinamento

Table 6 - Least square means and standard errors for feed conversion, expressed as $\mathrm{kg}$ of DM per $\mathrm{kg}$ of empty body weight gain (EBWTG) for control and compensatory growth treatments at different periods of feedlot

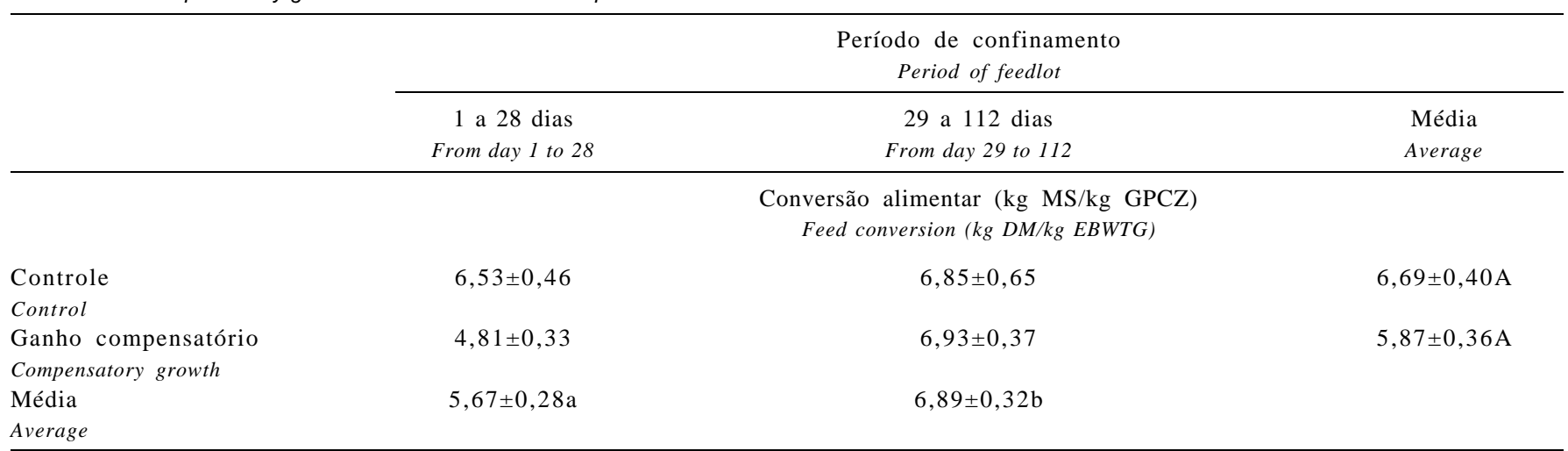

Médias seguidas, em cada linha (coluna), de mesma letra minúscula (maiúscula) não diferem $(P>0,05)$ pelo teste $F$.

Means in each row (column) followed by the same small (capital) letter, do not differ $(P>0.05)$ by F test. 
Maior eficiência inicial de utilização da energia dietética e, conseqüentemente, melhor conversão alimentar, como verificado neste trabalho, têm sido freqüentemente relatadas na literatura (Ryan, 1990; Hogg, 1991; Nicol \& Kitessa, 1995; Sainz, 1998) como resultado do menor conteúdo energético do peso ganho durante a fase inicial de realimentação e da menor exigência de energia de mantença dos animais, em decorrência da redução da massa de órgãos internos, metabolicamente ativos.

\section{Conclusões}

Os animais submetidos a um período de restrição alimentar em pastagem ganharam mais peso na fase inicial do período de realimentação em confinamento, como conseqüência do maior ganho de peso dos componentes nãocarcaça.

O maior ganho de peso corporal dos animais em crescimento compensatório não refletiu em maior ganho de peso de carcaça e, portanto, não contribuiu para elevação do valor comercial dos animais abatidos.

A partir do início do confinamento, com o fornecimento de concentrado, houve redução contínua do conteúdo de digesta do trato gastrintestinal, expresso como porcentagem do peso corporal.

Nos animais dos grupos controle e ganho compensatório, o início do confinamento foi o período de melhor conversão alimentar e coincidiu com o período de maior consumo alimentar por unidade de tamanho metabólico e em porcentagem de peso vivo.

\section{Literatura Citada}

AGRICULTURAL RESEARCH COUNCIL - ARC. The nutrient requirements of farm livestock. London: Commonwealth Agricultural Bureaux, 1980. 350p.

AGRICULTURAL AND FOOD RESEARCH COUNCIL - AFRC Energy and protein requirements of ruminants. Technical committee on responses to nutrients. Wallingford: $\mathrm{CAB}$ International, 1993. $159 \mathrm{p}$.

ALLEONI, G.F.; ABRANMIDES, P.L.G.; MATTOS, H.B. Efeito da suplementação protéica na perfomance de bovinos machos leiteiros mantidos em pastos consorciados. Boletim de Indústria Animal, v.30, n.1, p.33-45, 1980.
CAMPOS, O.F.; LIZIERE, R.S.; ALVES, P.A.P.M. et al. Experimento do CNPGL/EMBRAPA com abate de machinhos da raça Holandesa aos 6 meses de idade apresenta bons resultados. Gado Holandês, n.451, p.36-45, 1996.

ARSTENS, G.E.; JOHNSON, M.A.; ELLEMBERGER, M.A. et al. Physical and chemical components of the empty body during compensatory growth in beef steers. Journal of Animal Science, v.69, n.8, p.3251-3264, 1991.

HARVEY, W.R. Mixed models least squares and maximum likelihood computer program (LSMLWM). Versão PC - 2, Colombus: 1990. (CD-ROM).

HERSON, M.J.; HORN, G.W.; KREHBIEL, C.R. et al. Effect of life weight gain of steers during winter grazing: I. Feedlot performance, carcass characteristics, and body composition of beef steers. Journal of Animal Science, v.82, n.1, p.262272, 2004.

HOOG, B.W. Compensatory growth in ruminants. In: PEARSON, A.M.; DUTSON, T.R. (Eds.) Growth regulation in farm animals: advance in meat science research. Corvallis Oregone: Elsevier, 1991. v.7, p.103-134.

LAWRENCE, T.L.J.; FOWLER, V.R. Growth of farm animals. 2.ed. New York: CAB International, 1997. 330p.

LUCCI, C.S. Bovinos leiteiros jovens. São Paulo: Nobel/EDUSP, 1989. $371 \mathrm{p}$.

NATIONAL RESEARCH COUNCIL - NRC. Nutrient requirements of beef cattle. 7.ed. Washington, DC: National Academy Press, 1996. 242p.

NICOL, A.M.; KITESSA, S.M. Compensatory growth in cattle revisited. In: NEW ZELAND SOCIETY OF ANIMAL PRODUCTION SYMPOSIUM, 55., 1995, Otago. Proceedings... Otago University, 1995. p.157-160.

RYAN, W.J. Compensatory growth in the cattle and sheep. Nutrition Abstracts and Reviews (Series B), v.6, n.9, p.653-664, 1990.

SAINZ, R.D. Crescimento compensatório em bovinos. In: SIMPÓSIO SOBRE PRODUÇÃO INTENSIVA DE GADO DE CORTE, 1., 1998, Campinas. Anais... Campinas: Colégio Brasileiro de Nutrição Animal, 1998. p.22-38.

SILVA, D.J. Análise de alimentos (métodos químicos e biológicos). Viçosa, MG: Universidade Federal de Viçosa, 1990. 160p.

STEEL, R.G.D.; TORRIE, J.H. Principles and procedures of statistics - a biometrical approach. 2.ed. New York: McGraw Book Company, 1980. 633p.

YAMBAYAMBA, E.S.K.; PRICE, M.A.; FOXCROFT, G.R. Hormonal status, metabolic changes, and resting metabolic rate in beef heifers undergoing compensatory growth. Journal of Animal Science, v.74, n.1, p.57-69, 1996.
Recebido: 14/10/05 Aprovado: 20/11/06 